\title{
MULHERES QUILOMBOLAS NA COMUNIDADE DO CÓRREGO DO MEIO E A BUSCA PELA EDUCAÇÃO FORMAL
}

\author{
Tawani Mara de Sousa Paiva \\ Carmem Lúcia Eiterer \\ Ana Paula Vencato
}

\section{Resumo}

Este artigo apresenta análise de parte dos dados produzidos no contexto de pesquisa de mestrado acerca da experiência de mulheres quilombolas em espaços de educação formal e informal. Para tanto foram entrevistadas quatro mulheres quilombolas. A partir das entrevistas mobilizamos como eixos de análise as trajetórias educacionais e os sentidos da escolarização para as colaboradoras, levando em consideração marcadores como gênero, raça/etnia, classe e origem (quilombolas e do campo); a participação na Associação Comunidade Quilombola Córrego do Meio; a inserção no Cursinho Popular Quilombola Córrego do Meio e nos espaços de educação formal. A partir da pesquisa foi possível compreender que a sociedade desigual marcada pelo racismo, machismo e outros preconceitos, ofereceu obstáculos para as trajetórias escolares das entrevistadas. Entretanto, para essas mulheres quilombolas a educação está além da construída na escola, portanto, ela compreende os diversos ambientes sociais em que circulam. Mas, há em seus núcleos familiares uma mobilização em torno da construção de condições necessárias para a escolarização de seus/suas descendentes, visando a mobilidade social intergeracional.

Palavras-chave: mulheres quilombolas; sentidos da educação; trajetórias educacionais.

\section{QUILOMBOLA WOMEN IN THE CÓRREGO DO MEIO COMMUNITY AND THE SEARCH FOR FORMAL EDUCATION}

\section{Abstract}

This article presents part of the analysis of data produced in the context of master's research on the experience of quilombola women in spaces of formal and informal education. Four quilombola women were interviewed for this purpose. Based on the interviews, we mobilized the educational trajectories and meanings of schooling for the women collaborators, taking into consideration markers such as gender, race/ ethnicity, class and origin (quilombolas and rural); participation in the Association Comunidade Quilombola Córrego do Meio; insertion in the Cursinho Popular Quilombola - Córrego do Meio and in spaces of formal education. From the research it was possible to understand that the unequal society marked by racism, chovinism and other prejudices, offered obstacles to the school careers of the women interviewed. For these quilombola women, education is beyond what is built at school, therefore, it comprises the various social environments in which they circulate. However, there is a mobilization in their family around the construction of the necessary conditions for the schooling of their descendants, aiming at intergenerational social mobility.

Keywords: quilombola women; senses of education; educational trajectories

\section{MUJERES QUILOMBOLAS EN LA COMUNIDAD CÓRREGO DO MEIO Y LA BÚSQUEDA POR LA ENSEÑANZA FORMAL}

Resumen

El presente artículo presenta un análisis inicial de los datos obtenidos en la investigación de maestría sobre la experiencia de mujeres quilombolas (mujeres de los quilombos, comunidades tradicionales de familias 
de negros) en espacios de educación formal e informal. A partir de las entrevistas realizadas a cuatro mujeres quilombolas, se estableció el eje de análisis sobre las trayectorias educacionales y los sentidos de enseñanza de las mismas, teniendo en cuenta marcadores como: género, raza/etnia, clase y origen (quilombolas y rurales); la participación en la Asociación Comunidad Quilombola Córrego do Meio; la inserción en el Taller Popular Quilombola - Córrego do Meio y en los espacios de enseñanza informal. Los resultados provisionales posibilitan una comprensión de los obstáculos que la sociedad desigual, marcada por el racismo, machismo y otros prejuicios, ha significado para las trayectorias educativas de las entrevistadas. Para esas mujeres quilombolas, la enseñanza está más allá de la construida en educación institucional, por lo tanto, esta también comprende los diversos ambientes sociales en los que interactúan. A pesar de ello, siguen construyendo las condiciones necesarias para esta educación formal en sus núcleos familiares, en miras de una movilidad social intergeneracional.

Palabras clave: mujeres quilombolas, sentidos de la enseñanza, trayectorias educacionales

\section{INTRODUÇÃO}

Este artigo discute parte dos resultados de pesquisa de natureza qualitativa que buscou compreender os sentidos atribuídos por educandas e educadores à experiência do Cursinho Popular Quilombola - Córrego do Meio (CPQ-CM). Essa vivência surgiu em Paula Cândido em 2009, mas passou em 2015 a desenvolver suas atividades no Córrego do Meio por demanda da população, que se pautavam, entre outras, pela dificuldade de transporte para Paula Cândido aos sábados.

A Comunidade Quilombola Córrego do Meio, território onde o cursinho se desenvolveu, foi titulada em novembro de 2015 pela Fundação Cultural Palmares (FCP) depois do processo de aquilombar-se e da busca pelo reconhecimento do Estado. Aquilombar-se, segundo Bárbara Souza (2008), está relacionado ao movimento quilombola e à luta pelos direitos dos grupos. De acordo com a autora: "[...] aquilombar-se remete à luta contínua não pelo direito de sobreviver, mas pelo de existir em toda a sua plenitude. Trata-se da luta pela existência física, cultural, histórica, e social das comunidades quilombolas" (SOUZA, 2008, p. 171).

Para a realização da pesquisa foram entrevistadas quatro mulheres quilombolas e educandas do cursinho, quatro educadoras/es e quatro colaboradores/as. Neste artigo nos dedicamos à análise das vivências das quatro educandas quilombolas com os espaços de educação formal. A escolha das educandas foi realizada mediante a consulta das fichas de inscrição de 2015 e 2016. A partir das mesmas estipulamos um recorte: a idade superior aos 25 anos, tendo em vista as diferentes características da vida adulta, além da inserção na comunidade e seus papéis na mesma. Observamos que segundo a Organização Mundial da Saúde (OMS) a juventude vai até a idade de 29 anos (SILVA, SILVA, 2011). Entretanto, pelo modo de vida das pessoas pesquisadas, verificamos que aos 25 anos já assumem responsabilidades típicas da vida adulta como o cuidado de filhos e provimento material da família.

As entrevistadas são Cláudia, Gláucia, Patrícia e Aparecida1. As quatro mulheres participaram do cursinho como colaboradoras e educandas entre 2015 e 2016. Após a inserção no CPQ-CM, ocuparam espaços na educação formal de acordo com a sua respectiva escolaridade. As três primeiras foram para a EJA em Airões, comunidade onde se localiza o

\footnotetext{
${ }^{1}$ Utilizaremos ao longo do texto os nomes verdadeiros das colaboradoras, mediante a autorização destas, conforme explicitado metodologicamente em Paiva (2019).
} 
Córrego do Meio, e Aparecida entrou no curso de Licenciatura em Educação do Campo (LICENA) na UFV. Cláudia e Gláucia são de zonas rurais próximas e passaram a morar lá após seus casamentos. Já Patrícia e Aparecida nasceram e cresceram ali.

Diante dos recortes estipulados e tendo em vista a participação no cursinho, pudemos perceber que em 2015 este contava com maior participação de mulheres; sendo 26 mulheres e 13 homens e, entre as mulheres, 10 estavam no ensino fundamental (sendo quatro com fundamental incompleto e seis com fundamental completo); 15 dessas mulheres estavam no nível médio (10 no médio incompleto, cinco com o médio completo) e uma não informou a escolaridade. Dentre os homens, sete estavam no nível do ensino fundamental (seis com fundamental incompleto e um com ensino fundamental completo). Já seis deles estavam no ensino médio (cinco com nível incompleto e um com nível médio completo).

Já em 2016 os números totais são menores com 22 inscritas/os, mas o número de mulheres permanece maior em relação ao de homens, sendo 16 mulheres e seis homens. A escolaridade entre as mulheres era assim distribuída: duas com fundamental incompleto e 14 no nível médio (nove tinham médio incompleto e cinco o ensino médio completo). Entre os homens, quatro tinham o ensino fundamental incompleto, um o ensino médio incompleto e um não informou.

As trajetórias escolares descontinuas desta população nos remetem-nos ao fenômeno do epistemicídio, nos termos de Sueli Carneiro (2005, p. 100-101; p. 114): um aparato global de destruição de corpos, mentes e espíritos promovidos pelas normas de cognição consensuadas pelos racialmente hegemônicos. "O epistemicídio se realiza através de múltiplas ações que se articulam e se retroalimentam, relacionando-se tanto com o acesso e ou permanência no sistema educacional, como com o rebaixamento da capacidade cognitiva do alunado negro".

A finalidade do cursinho era preparar os/as estudantes para o ENEM e/ou vestibulares. Nesse sentido, pretendia atender estudantes do ensino médio ou os que estivessem concluindo o mesmo; porém, a análise das fichas de inscrição aponta para a existência do interesse de sujeitos de diferentes idades e níveis escolares, o que exigiu ampliar a metodologia para atendê-los.

A partir da análise das fichas de inscrição no biênio 2015-2016 percebemos ainda que, se comparadas aos homens, as mulheres são maioria no cursinho e a experiência dessas com o cursinho popular na comunidade significou a reaproximação com a sala de aula, ainda que informal. No âmbito da vida comunitária foi possível perceber, pelo trabalho de campo, a presença significativa das mulheres nos espaços de organização da comunidade, como a Associação Comunidade Quilombola de Córrego do Meio (ACQCM) e as festividades, como a celebração de 13 de maio e a Festa do Rosário no mês de outubro, por exemplo. As mulheres, atuam, portanto, como guardiãs da cultura na comunidade.

\section{SER MULHER, NEGRA E QUILOMBOLA: OS ATRAVESSAMENTOS SOCIAIS QUE INTERPÕEM BARREIRAS PARA OS MARCADORES IDENTITÁRIOS}

Marcadores sociais da diferença é um campo de estudos que visa compreender como, na sociedade, são produzidas as desigualdades e hierarquias entre as pessoas. Embora refira-se a categorias socialmente construídas, essas diferenças são usualmente percebidas como "naturais", por exemplo: gênero, sexualidade, raça/etnia, geração e classe social. Raça e gênero são operadores de diferenças que se refletem no mundo do trabalho já que a maior parte do contingente de mulheres no emprego doméstico no Brasil são negras (pretas e pardas) (IPEA, 
2011). A inserção das mulheres pobres precariamente escolarizadas no mundo do trabalho se faz como empregadas domésticas e babás e/ou como auxiliares nas tarefas no campo.

Como nos aponta Carla Akotirene (2019) é necessária uma leitura interseccional ao se pensar a realidade das mulheres negras. Isso porque possuem como marcadores sociais da diferença a sua negritude, a classe social e o gênero: a sociedade fundamentalmente machista, racista e classista lhes opõe diferentes barreiras. Diferente do que prega o imaginário social brasileiro, fundamentado na perspectiva do mito da democracia racial, a essas mulheres são concedidos os lugares mais subalternizados. Desse modo, quando uma trajetória de mulher negra foge a essa "regra", é tida como exceção. Ainda de acordo com a autora, "[...] vistas pelas lentes de raça, as mulheres negras aguentam dor física; por classe são vistas como protótipos da feminização da pobreza e atravessam gerações sendo chefas de famílias, vitoriosas das dificuldades impostas pelo imperialismo colonial" (AKOTIRENE, 2019, p. 79).

O debate sobre relações raciais e racismo na sociedade - e academia - brasileira é extenso. Diversos autores e autoras vêm trabalhado para compreender este debate, suas raízes, práticas, reflexos e consequências do racismo no Brasil (GUIMARÃES, 2004; HOFBAUER, 2006; DA COSTA SILVA, 2013). Conforme Ângela Figueiredo e Ramón Grosfoguel (2009, p. 228), “[...] ainda que a maioria dos brasileiros reconheça que o Brasil é uma sociedade desigual racialmente, há controvérsias não somente acerca dos motivos ou da origem da desigualdade racial e da forma de combatê-la. Desde as pesquisas desenvolvidas por Florestan Fernandes, temos conhecimento de que os brasileiros têm preconceito de ter preconceito". Nesse sentido, Lilia Schwarcz (2001, p. 76), ao analisar dados de pesquisa realizada pela USP em 1988, revela que:

[...] 97\% dos entrevistados afirmaram não ter preconceito, 98\% disseram conhecer, sim, pessoas e situações que revelam a existência de preconceito racial no país. Ao mesmo tempo, quando inquiridos sobre o grau de relação com aqueles que denominam racistas, os entrevistados indicaram com frequência parentes próximos, namorados e amigos íntimos. A conclusão informal da pesquisa era, assim, que todo brasileiro parece se sentir como uma 'ilha de democracia' cercado de racistas por todos os lados.

Sendo o Brasil um país marcado historicamente pelo racismo e machismo, pensar na condição de mulher negra e quilombola é relacionar diferentes formas de violência e preconceitos destinados a um determinado grupo social. Bebel Nepomuceno (2013, p. 389) aponta que a desigualdade de gênero e raça tem origens no período colonial, ela destaca a relação do trabalho da mulher negra com a escolarização tendo em vista que, “[...] no pós abolição, por conta do racismo existente na sociedade, essa população encontrou dificuldade de obter um lugar nos bancos escolares da rede pública".

Assim como no caso do racismo, há vários estudos que versam sobre o machismo, a desigualdade de gênero e os efeitos de uma lógica patriarcal que não se dissipou por completo no país e que teve fortes raízes nas práticas sociais desde o período colonial (ver, por exemplo, SAFFIOTI, 1979, 1992, 2009). Essas lógicas impactam questões como o uso do tempo destinado ao trabalho remunerado (fora de casa); doméstico (dentro de casa) e o tempo superior destinado ao lazer de homens sobre as mulheres desde a infância (RAMOS, 2009). Com relação ao trabalho doméstico ou de cuidado, remunerado ou não, também são as mulheres que ocupam majoritariamente essas funções (SORJ, 2014).

Laís Abramo (2006, p. 41) reforça que desigualdades de gênero e raça estruturam a permanência e reprodução da desigualdade social no Brasil. Conforme a autora, grande parte da

Revista Teias v. $21 \cdot$ n. $62 \cdot j u l . /$ set. $2020 \bullet$ Seção Temática Raça ecultura 
população feminina se dedica aos postos mais precários de trabalho, sem remuneração ou sem direitos trabalhistas, dentre estas as negras são maioria.

A porcentagem de mulheres ocupadas no serviço doméstico (18\%) está entre as mais altas entre os países latino-americanos. Se somamos a isso a porcentagem de ocupadas sem remuneração (15\%), chegamos a uma cifra de $33 \%$. Isso significa que um terço das mulheres que trabalham no Brasil ou não recebem nenhuma remuneração pelo seu trabalho ou estão ocupadas no serviço doméstico. Além disso, do total de ocupadas no serviço doméstico, apenas $27 \%$ têm carteira assinada (ou seja, mais de $2 / 3$ delas não estão registradas e não gozam dos benefícios previstos na legislação do trabalho). Em todas essas formas precárias de ocupação as mulheres negras estão sobrerepresentadas em relação às brancas: a porcentagem das que estão empregadas no serviço doméstico é $23,3 \%$, e a de ocupadas sem remuneração é de $17,5 \%$, o que soma $40,8 \%$. Entre as trabalhadoras no serviço doméstico, $71,2 \%$ das brancas e $76,2 \%$ das negras não têm carteira assinada.

O contato das mulheres colaboradoras deste estudo com o cursinho se deu pelas tarefas da Associação Quilombola. De acordo com as divisões de tarefas, as mulheres eram responsabilizadas pela abertura do casebre, local onde a experiência acontecia, e o preparo do café no período da manhã. A prefeitura organizava o transporte e alguns materiais como cadeira e livros, necessários na elaboração das aulas.

Assim, o Cursinho Popular Quilombola Córrego do Meio foi o contato mais próximo que elas tiveram com os conteúdos escolares após anos afastadas da escola. A importância da escolarização para elas sobressai quando estas declaram as escolaridades de seus filhos. Gláucia destaca que estão todos estudando dentro da faixa de correspondência idade/ano. Cláudia, por sua vez, afirma que, dos cinco filhos e filhas, apenas três estão na escola, porque os mais velhos já estão formados. Já Patrícia tem dois filhos formados em técnico de agropecuária na Escola Família Agrícola (EFA) de Ervália, um inserido no ensino superior na UFV (LICENA) e o mais novo que também estuda em EFA.

Seguindo a perspectiva da busca pela (re)existência de seus núcleos familiares, podemos apontar a trajetória escolar contínua de seus filhos e filhas e a oferta de condições para o desenvolvimento de seus estudos como um dos principais pontos de preocupação dessas mulheres e de seus maridos. Prevalece a concepção de que é através do estudo que se alcança postos de trabalho mais qualificados.

O trabalho está presente na vida das mulheres quilombolas de diferentes formas e inclui a atuação dentro da própria comunidade, nas Associações. Elas constroem os movimentos relacionados a sua cultura, como a Festa do Rosário e o 13 de maio. A participação dessas mulheres, no entanto não se restringe ao preparo de alimentos. Um exemplo disso é a presença marcante delas nas duas gestões da Associação e a sua contribuição no processo de certificação. Processo que tem início a partir da articulação realizada por Mestre Boi (mestre da Banda de Congo José Lúcio Rocha) em 2014.

Há, nas suas narrativas, a preocupação quanto a organizar o tempo da participação nos espaços comunitários em relação às demandas de suas famílias. Foi possível perceber uma divisão das tarefas no ambiente doméstico, principalmente nas residências de Gláucia e Patrícia, que possuem apenas filhos. Eles ajudam na organização da casa, no processo de pegar e cortar lenha e na cozinha. Contudo, tal como afirma Gláucia, “[...] eu aqui na comunidade eu participo de 
muitas coisas, seja pra receber pessoas, aqui em casa, coisas que eu faço e eles não entendem. Não adianta eu fazer um bem pro outro e arrumar briga aqui em casa, tudo que tem e volta no mesmo dia eu topo" (Gláucia, entrevista em 26 ago. 2018). Ou seja, ela explica que não assume aquilo que a obrigar a se ausentar de casa para pernoite fora.

Como aponta, ainda pequena foi morar no Rio de Janeiro para cuidar do avô "[...] meu avô ficou viúvo e ficou doente [...] ficamos lá quatro anos. Aí ele faleceu, nós voltamos pra trás" (Gláucia, entrevista em 17 abr. 2018). Conforme Helena Hirata há uma divisão sexual do trabalho nessas práticas de cuidado, em que:

[...] os cuidadores são majoritariamente mulheres, pobres, negras, muitas vezes migrantes (provenientes de migração interna ou externa). Por ser "um conjunto de práticas materiais e psicológicas que consiste em trazer respostas concretas às necessidades dos outros", o trabalho de cuidador de idosos, crianças, doentes, deficientes físicos e mentais foi exercido durante muito tempo por mulheres, no interior do espaço doméstico, na esfera dita "privada", de forma gratuita e realizado por amor (HIRATA, 2016, p. 64).

Tomando a narrativa de trajetórias apresentadas por essas mulheres, podemos ressaltar que a dimensão da (re)existência do círculo familiar possui uma importância central para elas desde a sua infância.

Associada a essa necessidade do cuidado, a questão do trabalho desde a infância também aparece na narrativa de Cláudia. "Nós somos cinco irmãs. Eu sou a mais velha de todas. E eu tinha que trabalhar pra ajudar, trabalhava na roça e na casa dos outros, uai! Botá meus irmãos na onde eles tão agora" (Cláudia, entrevista em 17 abr. 2018); interrompeu os estudos, na então quarta série, para ajudar o pai a cuidar dos irmãos. E percebemos, nesse aspecto, uma divisão familiar na qual a mulher ocupa o lugar do cuidado para que os sujeitos de sua família possam construir trajetórias diferentes, ou seja, possam estudar.

Levando em consideração as trajetórias escolares das mulheres entrevistadas, somente uma, Aparecida, concluiu sua trajetória na educação básica e se encontrava no ensino superior. Já Cláudia, Gláucia e Patrícia cursavam o fundamental II na modalidade educação de jovens e adultos (EJA), em Airões. Patrícia trabalha como doméstica em Viçosa e vende os produtos de sua horta. Aparecida também comercializa os produtos de sua horta, mas tem a perspectiva de trabalhar como professora na escola da comunidade. Abordaremos mais a fundo o processo de escolarização dessas mulheres no próximo tópico.

As trajetórias das mulheres quilombolas nos espaços de educação formal

A partir da escolha das mulheres quilombolas colaboradoras na pesquisa, durante o trabalho de campo realizado no Córrego do Meio, realizamos entrevistas semiestruturadas. A análise das entrevistas nos permitiu estabelecer eixos de análise, como: as trajetórias dessas mulheres nos espações de educação formal e os sentidos atribuídos por elas à escolarização.

Podemos afirmar que há uma proximidade entre trajetórias de Gláucia, Patrícia e Cláudia no tocante a ocupação de espaços formais de educação. Gláucia vive na comunidade com seu marido e seus três filhos em uma casa ao lado de sua sogra. É a mais nova das mulheres entre seus irmãos e irmãs. Ela exerce diferentes atividades como plantar, capinar, colher, criar animais, além do crochê. Começou a trabalhar muito jovem e, na sua fala, coloca a dualidade concorrente do trabalho e da escola desde quando era criança.

Revista Teias v. $21 \cdot$ n. $62 \cdot j u l /$ set. $2020 \cdot$ Seção Temática Raça e cultura 
Já era também um estudo sofrido... desde nove anos eu já tinha que capinar, né? Então quando chegava em casa, tinha que ir pra escola... e aí tinha dia que os professor falavam que tinha prova e aí eu já ia lendo pelo caminho, pra num ganhar zero, né? [...]. Porque, sem tempo pra estudar, lendo pelo caminho afora que eu tinha que andar quase um hora da minha casa pra escola lá no Nova Viçosa, a gente saía seis horas lá de casa pra sete horas a gente tá chegando lá na escola. E tinha dia que a gente chegava atrasada, porque saía atrasado de casa (Gláucia, entrevista em 26 ago. 2018).

Nesse trecho da entrevista, Gláucia (entrevista em 26 ago. 2018) relata algumas das dificuldades vivenciadas em sua infância; dificuldades são comumente associadas a mulheres oriundas de famílias de trabalhadores do campo. Como ela afirma, "[...] o tempo que eu cresci foi aquele tempo que arroz e frango era no domingo, né? Quem tinha, né?”. Diante dessa realidade, além de buscar o estudo, existia uma necessidade material a ser superada por ela através do seu trabalho.

Vimos que Cláudia também ingressou no mundo do trabalho precocemente e não prosseguiu com seus estudos; hoje tem cinco filhos e vive na comunidade com seu marido. Ela trabalha na roça, planta, colhe e também costura. Patrícia (entrevista em 4 maio 2018) afirma que é "nascida e criada na comunidade". Ela vive com seu marido, tem quatro filhos, trabalha como doméstica em Viçosa, também planta e colhe. Relata também o ingresso precoce no mundo do trabalho. Patrícia possui sete irmãos, sendo que três vivem na comunidade e em Airões e os outros quatro moram no Rio de Janeiro com seu pai. Sua trajetória tem em comum com as demais a relação conflituosa entre trabalho e estudo, bem como a necessidade de apoiar seu núcleo familiar. Quando interrogada sobre os estudos, ela afirma: "Olha, essa parte eu nem lembro direito. Porque eu estudei e aí eu saí pra trabalhar, porque acabou que minha mãe faleceu, e aí a gente foi criado pela avó e minha vó não tinha tanta condição de criar três netos com salário mínimo, então eu acabei saindo cedo pra trabalhar" (Patrícia, entrevista em 4 maio 2018).

Foi ainda possível compreender que Aparecida, quarta mulher entrevistada, teve uma trajetória diferente das demais. Nascida e criada na comunidade com seus pais e irmãos, hoje ela trabalha no cultivo da terra, na colheita de café e vive com seu marido, Júlio. Ela é a única educanda que cursou todo o ensino fundamental e médio, mas é uma exceção na sua família. De acordo com ela, "[...] meus irmãos, a maioria parou no fundamental. Que é: minha irmã, meu irmão caçula, que é marido da Cláudia, e o que mora lá em Viçosa, Isaías. E tem o Zé Francisco, que tirou o fundamental, mas num tirou o médio, e o caçula começou o ensino médio, mas parou também" (Aparecida, entrevista em 17 abr. 2018). Em outro ponto trata da questão do incentivo do seu pai e, também, da sua mãe, ela afirma que:

Meu pai, igual eu tava falando outro dia, ele sempre me apoiou, né? Quando eu ia sair do ensino médio ele faleceu. Aí ficou só eu e minha mãe e eu na época eu tentei o vestibular e não consegui passar. Aí eu meio que dei uma parada assim, mas ele sempre me apoiou. Igual quando eu estudava lá em Paula Cândido à noite, ele me buscava todo dia depois do trabalho lá em baixo pra eu não subir sozinha (Aparecida, entrevista 17 abr. 2018).

Vemos que, após a experiência de sua participação no cursinho popular, as trajetórias dessas mulheres as levaram a ocupar lugares distintos na educação formal. As três primeiras ingressaram na EJA que teve início em Airões em meados de 2016 e Aparecida cursou no ensino 
superior público o curso de Licenciatura em Educação do Campo (LICENA) na UFV, concluído em 2020

\section{Os sentidos da escolarização}

Como colocado acima, um dos eixos emergentes na análise das entrevistas foi o dos sentidos da escolarização. A mobilização dos sentidos se funda na concepção que Jorge Larrosa (2002) nos traz sobre a experiência e o significado da experiência. Em suas palavras, "[...] a experiência é o que nos passa, o que nos acontece, o que nos toca" (LARROSA, 2002, p. 21). A partir do entendimento do que é experiência, faz-se essencial também trazermos a ideia do sujeito da experiência. De acordo com o autor:

O sujeito da experiência seria algo como um território de passagem, algo como uma superfície sensível que aquilo que acontece afeta de algum modo, produz alguns afetos, inscreve algumas marcas, deixa alguns vestígios, alguns efeitos (LARROSA, 2002, p. 24).

Para as mulheres quilombolas participantes da pesquisa, o valor da educação se relaciona com a preocupação com a escolarização, mas também há, ainda, uma perspectiva mais ampla, ou seja, além da escolarização, entendem que a educação é adquirida nos diferentes espaços de socialização, de trabalho e de organização política. Há, na trajetória dessas mulheres, a experiência da participação em Associações, na realização de eventos e na mobilização dos sujeitos quilombolas para o processo de certificação e as demandas da comunidade.

Durante o trabalho de campo, percebemos que há uma participação dos filhos nas tarefas domésticas, mas há uma mobilização familiar para atender as demandas da escola e/ou universidade (ambas inseridas na pedagogia da alternância). Ainda assim, quando interpeladas sobre a educação, elas nos trazem uma compreensão mais ampla. Tal como aponta Cláudia, "[...] a educação é o que vem do berço, ela é ótima, até pra conversar com as pessoas você tem que ter educação" (Cláudia, entrevista em 17 abr. 2018).

Para além de ajudar na educação de seus filhos, Patrícia relaciona a sua experiência de educação com a sua forma de enxergar a vida.

Antes eu tinha dificuldade de ensinar lição de casa, você tinha que quebrar a cabeça pra ajudar eles entender o que é. Então quando você volta a estudar, você tem mais claro isso. $\mathrm{E}$ até mesmo com a vida você consegue raciocinar mais, você conhece aprender mais coisa, você conhece interpretar mais coisas, que eu acho no meu caso foi muito interessante, que eu consegui ver as coisas de um outro jeito diferente. Então eu pretendo continuar mais um cadinho, pelo menos até o ensino médio (Patrícia, entrevista em 4 maio 2018).

A sua trajetória é marcada por conhecimentos adquiridos em suas relações sociais, no trabalho, na lida com a terra. Nesse sentido, a educação escolar vem se agregar a tudo isso, ajudando a enxergar mais. Já Aparecida, que tem acesso à universidade, afirma:

Eu acho que a educação é fundamental, a questão da educação é fundamental, não no sentido de falar "ah, fulano é estudado". Acho que educação é você saber o que é e progredir em cima daquilo. Às vezes tem muita gente que é formado, tem doutorado, mas num sabe nem pra que caminho seguir. Igual eu tava conversando com Pedro (irmão, marido de Cláudia) outro dia, a questão da formação num é só o fato de você ir lá, tá na sala de aula, entrar na 
universidade, sair de lá e "vou pra onde agora?", "não sei nem pra onde que eu vou". Eu acho que o fato de você ir lá buscar informação, casar com sua vida, casar com a sociedade, o que é que tá com a sociedade, eu acho que isso é fundamental (Aparecida, entrevista em 17 abr. 2018).

Mesmo quando se trata da educação formal, como aponta Aparecida, a relação estabelecida precisa ser compreendia numa perspectiva mais ampla, relacionando-se com a vida, a sociedade. Assim, é necessário pensar nos múltiplos espaços de formação que essas mulheres frequentaram nas suas trajetórias e sua participação na Associação da Comunidade Quilombola de Córrego do Meio se faz relevante.

Todas as educandas entrevistadas participaram enquanto secretárias, tesoureira e/ou presidenta da associação. E, através do processo de certificação, entraram em contato com espaços de discussão em torno do histórico da comunidade; coleta de assinaturas, mobilizações de reuniões e comemorações, redação de atas e organização de documentos. Essas atividades colocam essas mulheres à frente de diferentes demandas relativas a esse processo de certificação, que foi intensificado entre 2014 e $2018^{2}$. Muitas destas atividades passam pela mediação da palavra escrita e seus usos institucionais. De acordo com Patrícia, assim como Cláudia, ela participou como secretária da primeira gestão da Associação.

Essa experiência vivenciada por Patrícia, Aparecida, Cláudia e Gláucia, as aproxima, por exemplo, do processo de escrita, através da organização das atas nas reuniões da associação, do contato com a documentação necessária para a certificação da Comunidade. A dimensão organizacional da comunidade tem uma participação significativa dessas mulheres. A normatização da escrita passa a ter um grau de importância elevado se comparado a outros espaços de organização. Cláudia nos falou um pouco sobre esse processo de registro de reuniões no Córrego do Meio e, também, sobre a sua participação em diferentes gestões da ACQCM:

Eu sou uma das primeiras secretárias, da segunda associação; da primeira era Aparecida. Da segunda agora que ela resolveu me colocar como coisa. Mas eu também não queria não, mas a gente tem que fazer parte de alguma coisa, né? Tem que ficar escrevendo, os outros falando e a gente escrevendo, num pode escrever errado (risos) (Cláudia, entrevista 17 abr. 2018).

Nas reuniões da Associação a presença de artefatos como caderno e caneta são imprescindíveis. Além disso, ao final, o protocolo exige que seja realizada a leitura da Ata e depois todas/os participantes a assinam, confirmando a presença e manifestando a concordância com o registro. A importância da escrita é explicita nesses eventos.

Em 2016, com a chegada da EJA em Airões, algumas delas tiveram acesso ao ensino fundamental de forma institucionalizada, formal, percorrendo o trajeto até a escola sozinhas ou, como Gláucia afirma, "[...] caminhar pelo caminho, com Deus". Sobre a experiência na EJA, Patrícia (entrevista em 4 maio 2018) afirma:

Mas assim, eu gosto sabe? Tem uns que falam: eu não vou continuar estudando, porque aí eu vou, eu não tô saindo bem na matemática. Ué, você não sai bem na matemática, mas você vai bem em outras matérias. Igual por

\footnotetext{
2 Os estudos de Ferreira (2016), assim como Reis (2014), exploram as relações entre posições de lideranças comunitárias ocupadas por mulheres e usos da escrita.
} 
exemplo, igual eu falei, matemática e inglês pra mim é complicado, mas eu já gosto do português, eu já gosto da história, entendeu?

O apoio da família é um ponto importante nas suas trajetórias, inclusive para a mobilidade até a escola. Patrícia e Gláucia são vizinhas e, portanto, faziam a caminhada juntas. O caminho percorrido por Cláudia é diferente e seu marido e filhos se responsabilizavam por acompanhá-la ao final da aula. "Quando Alisson (filho) taí, ele vai lá comigo mais cedo pra escola e fica lá... Agora ontem ele (esposo) me buscou” (Cláudia, entrevista em 17 abr. 2018).

Assim, a escolha dos sujeitos da pesquisa (a partir do recorte de gênero e idade), realizado a partir das fichas de inscrição e do nosso trabalho de campo, proporcionou-nos analisar o cursinho na perspectiva do processo de desigualdades de oportunidades escolares relacionados também, por sua vez, à classe, raça, geração e à localidade. Além disso, estivemos diante de representações distintas da educação, tendo em vista as "leituras de mundo" que essas mulheres constroem e mobilizam ao longo de suas trajetórias.

\section{CONSIDERAÇÕES FINAIS}

A partir da realização da pesquisa e da análise das entrevistas, bem como da revisão bibliográfica, podemos afirmar que tendo em vista os pertencimentos de gênero, raça/etnia e classe na sociedade brasileira, marcada pela desigualdade e por preconceitos, Gláucia, Aparecida, Cláudia e Patrícia enfrentaram diversos entraves nas suas trajetórias escolares. Nesse sentido, historicamente, a interseccionalidade entre gênero, classe e raça, para além da própria localidade em que essas mulheres constituíram suas famílias e vidas, significaram enfrentar barreiras com as quais tiveram que conviver. Essas mulheres, negras e quilombolas, habitantes uma zona rural, viram-se distantes física e simbolicamente dos espaços de educação formal.

A articulação entre pobreza, trabalho infanto-juvenil e abandono da escola formal para manutenção familiar esteve presente em suas trajetórias desde a infância. Como apontado acima, na análise, foi possível perceber as similaridades entre as experiências da maioria das mulheres entrevistadas: apenas uma conclui os estudos em idade regular e hoje se encontra formada numa instituição pública de ensino superior.

Podemos afirmar que a luta das mulheres e homens quilombolas e do povo negro, como um todo, pela educação escolar, relaciona-se com um complexo processo histórico de discriminação racial e de gênero ao qual a sociedade submete esses sujeitos. Ao povo negro são destinados postos de trabalho de baixa qualificação e pouco prestígio social. Em contrapartida, há uma busca, por parte desses sujeitos, pela educação formal. Entre as reinvindicações, a educação escolar se tornou prioritária, pois o analfabetismo e a lenta inserção nas escolas oficiais se constituíam em um dos principais problemas dessa população para a inserção no mundo do trabalho (GOMES, 2017, p. 29).

Isso pode ser percebido nas narrativas das mulheres entrevistadas que são mães tendo em vista a construção de uma realidade diferente para seus/suas filhos/as. Ou seja, a difícil conciliação entre trabalho e educação, se depender dessas mulheres, não estará posta para essa nova geração. Por fim, mesmo que compreendam a educação num aspecto mais amplo, abarcando suas vivências em diferentes espaços sociais, essas mulheres buscam a educação escolar formal e a entendem como aliada em suas atividades. 


\section{REFERÊNCIAS}

ABRAMO, Laís. Desigualdades de gênero e raça no mercado de trabalho brasileiro. Cienc. Cult., São Paulo, v. 58, n. 4, p. 40-41, dez. 2006. Disponível em http://cienciaecultura.bvs.br/pdf/cic/v58n4/a20v58n4.pdf. Acesso em 5 fev. 2020.

AKOTIRENE, Carla. Interseccionalidade. São Paulo: Sueli Carneiro; Pólen, 2019.

CARNEIRO, Aparecida Sueli. A construção do outro como não-ser como fundamento do ser. $340 \mathrm{fl}$. Tese. Doutorado em Educação, Faculdade de Educação, USP, São Paulo, 2005.

CARNEIRO, Sueli. Mulheres em movimento. In: Estudos Avançados, São Paulo, v. 17, n. 49, p. 117-132, set./dez. 2003. Disponível em http://www.scielo.br/pdf/ea/v17n49/18400.pdf. Acesso em 5 fev. 2020.

COSTA SILVA, René Marc da. A Constituição de 1988 e a discriminação racial e de gênero no mercado de trabalho no Brasil. Int. Law: Rev. Colomb. Derecho Int., Bogotá, n. 23, p. 235-266, Dec. 2013. Disponível em http://www.scielo.org.co/pdf/ilrdi/n23/n23a08.pdf. Acesso em 5 fev. 2020.

DAVIS, Angela Yvonne. Mulheres, raça e classe. São Paulo: Boitempo, 2016.

FIGUEIREDO, Ângela; GROSFOGUEL, Ramón. Racismo à brasileira ou racismo sem racistas: colonialidade do poder e a negação do racismo no espaço universitário. Soc. e Cult., Goiânia, v. 12, n. 2, p. 223-234, jul./dez. 2009. Disponível em http://www.redeacaoafirmativa.ceao.ufba.br/uploads/ufg artigo 2009 AFigueiredo RGrosfog uel.pdf. Acesso em 5 fev. 2020.

FERREIRA, Maria Raquel Dias Sales. Mulheres quilombolas e culturas do escrito: voz e letra na comunidade quilombola do Mato do Tição/MG. 230fl. Dissertação. Mestrado em Educação, Conhecimento e Inclusão Social, Faculdade de Educação, Universidade Federal de Minas Gerais, Belo Horizonte, 2016.

GOMES, Nilma Lino. O movimento negro educador: saberes construídos nas lutas por emancipação. Petrópolis, Rio de Janeiro: Vozes, 2017.

GUEDES, Ana Célia Barbosa; SALGADO, Mayany Soares. Mulheres Quilombolas: Breves considerações sobre gênero, raça e geração no quilombo de Santa Rida da Barreira. In: XI Encontro Regional Nordeste de História Oral, 2017. Fortaleza. Anais. Fortaleza: Universidade Federal do Ceará, 2017. Disponível http://www.nordeste2017.historiaoral.org.br/site/anaiscomplementares2. Acesso em 14 nov. 2018.

GUIMARÃES, Antonio Sérgio Alfredo. Preconceito de cor e racismo no Brasil. Rev. Antropol., São Paulo, v. 47, n. 1, p. 9-43, 2004. Disponível em http://www.scielo.br/pdf/ra/v47n1/a01v47n1.pdf. Acesso em 5 fev. 2020.

HANCHARD, Michael G. Taking exception: narratives of racial equality in Brazil, Mexico and Cuba. Seminário Internacional Racismo e Relações Raciais nos Países da Diáspora Africana. Rio de Janeiro: Centro de Estudos Afio-Asiáticos, abr. 1992.

HASENBALG, Carlos. Entre o mito e os fatos: racismo e relações raciais no Brasil. In: MAIO, Marcos Chor; SANTOS, Ricardo Ventura (orgs.) Raça, ciência e sociedade. Rio de Janeiro: Ed. FIOCRUZ; CCBB, 1996, p. 235-249. Disponível em http://books.scielo.org/id/djnty/pdf/maio-9788575415177-16.pdf. Acesso em 3 fev. 2020. 
HIRATA, Helena. O trabalho de cuidado: comparando Brasil, França e Japão. SUR 24, v. 13, n. 24, p. 53-64, 2016. Disponível em https://sur.conectas.org/wp-content/uploads/2017/02/5sur-24-por-helena-hirata.pdf. Acesso em 4 fev. 2020.

HOFBAUER, Andreas. Ações afirmativas e o debate sobre racismo no Brasil. Lua Nova, São Paulo, 68: p. 9-56, 2006. Disponível em http://flacso.redelivre.org.br/files/2013/03/1064.pdf. Acesso em 5 fev. 2020.

HOOKS, bell. E eи não sou uma mulher? Mulheres negras e feminismo. Rio de Janeiro, Rosa dos Tempos, 2019.

INSTITUTO DE PESQUISA ECONÔMICA APLICADA (IPEA). Retrato das desigualdades de gênero $e$ raça. 4. ed. Brasilia, 2011. Disponível em http://www.ipea.gov.br/retrato/indicadores_trabalho_domestico_remunerado.html. Acesso em 16 fev. 2020.

LARROSA, Jorge B. Notas sobre a experiência e o saber de experiência. In: Revista Brasileira de Educação. $\quad$ n. 19, p. 20-28, 2002. Disponível em http://www.scielo.br/pdf/rbedu/n19/n19a02.pdf. Acesso em 5 fev. 2020.

LOURO, Guacira Lopes. Gênero, sexualidade e educação: uma perspectiva pós-estruturalista. 3. ed. Petrópolis: Vozes, 1999.

NEPOMUCENO, Bebel. Mulheres negras - protagonismo ignorado. In: PINSKY, Carla Bassenezi; PEDRO, Joana Maria (org.). Nova história das mulberes. São Paulo: Contexto, 2013, p. 382-409.

PAIVA, Tawani Mara de Sousa. Travessia: as experiências de educandas e educadoras/es no cursinho popular quilombola - Córrego do Meio. 165f. Dissertação. (Mestrado em Educação) Faculdade de Educação, Universidade Federal de Minas Gerais, Belo Horizonte, 2019.

RAMOS, Daniela Peixoto. Pesquisas de usos do tempo: um instrumento para aferir as desigualdades de gênero. Rev. Estud. Fem., Florianópolis, v. 17, n. 3, p. 861-870, dez. 2009. Disponível em http://www.scielo.br/pdf/ref/v17n3/v17n3a14.pdf. Acesso em 5 fev. 2020.

REIS, Sônia Maria Alves de Oliveira. Mulheres camponesas e culturas do escrito: trajetórias de lideranças comunitárias construídas nas CEBS, Belo Horizonte/MG: 261f. Tese. Doutorado em Educação, Universidade Federal de Minas Gerais, Belo Horizonte, 2014.

SAFFIOTI, Heleieth. A mulher na sociedade de classes: mitos e realidade. Rio de Janeiro: Rocco, 1979.

SAFFIOTI, Heleieth. Ontogênese e filogênese do gênero: ordem patriarcal de gênero e a violência masculina contra mulheres. Série Estudos/Ciências Sociais/FLACSO-Brasil. 2009. Disponível em http://flacso.redelivre.org.br/files/2015/03/Heleieth Saffioti.pdf. Acesso em 5 fev. 2020.

SAFFIOTI, Heleieth. Rearticulando gênero e classe social. In: COSTA, Albertina de Oliveira, BRUSCHINI, Cristina (orgs.) Uma questão de gênero. Rio de Janeiro: Editora Rosa dos Tempos, 1992. p. 183-215.

SCHWARCZ, Lilia Moritz. Racismo no Brasil. São Paulo: Publifolha, 2001.

SILVA, Roselani Sodré da; SILVA, Vini Rabassa da. Política Nacional de Juventude: trajetória e desafios. Cad. CRH, Salvador, v. 24, n. 63, p. 663-678, dez. 2011. Disponível em http://www.scielo.br/pdf/ccrh/v24n63/13.pdf. Acesso em 16 fev. 2020. 
SORJ, Bila. Socialização do cuidado e desigualdades sociais. Tempo soc., São Paulo, v. 26, n. 1, p. 123-128, jun. 2014. Disponível em http://www.scielo.br/pdf/ts/v26n1/09.pdf. Acesso em 5 fev. 2020.

SOUZA, Bárbara Oliveira. Aquilombar-se: panorama histórico, identitário e político do Movimento Quilombola Brasileiro. 204f. Dissertação. Mestrado em Antropologia Social, Universidade de Brasília, Brasília, 2018.

WHITAKER, Dulce Consuelo Andreatta. Da "invenção" do vestibular aos cursinhos populares: um desafio para a Orientação Profissional. Revista Brasileira de Orientação Profissional. v. 11, n. 2, p. 289-297. jul./dez.

2010.

Disponível em http://pepsic.bvsalud.org/pdf/rbop/v11n2/v11n2a13.pdf. Acesso em 15 jul. 2018.

Submetido em fevereiro de 2020 Aprovado em julho de 2020

\section{Informações das autoras}

Tawani Mara de Sousa Paiva

Secretaria de Educação do Estado de Minas Gerais

E-mail: tawanimsp@gmail.com

ORCID: https://orcid.org/0000-0002-2184-9631

Link Lattes: http://lattes.cnpq.br/0719526400095206

Carmem Lúcia Eiterer

Universidade Federal de Minas Gerais

E-mail: eiterercarmem@gmail.com

ORCID: https://orcid.org/0000-0002-6978-155X

Link Lattes: http://lattes.cnpq.br/9905263965506713

Ana Paula Vencato

Universidade Federal de Minas Gerais

E-mail: apvencato@gmail.com

ORCID: https://orcid.org/0000-0001-6602-2948

Link Lattes: http://lattes.cnpq.br/0542304469914856 